\title{
Cancer related PTSD symptoms in patients of all ages and their relatives, and general risk factors
}

\author{
Monika Paleczna
}

Since the DSM-IV, a life threatening disease is considered as a potential source of PTSD. One of the core elements of the diagnosis is experiencing a traumatic event or being a witness of a close person experiencing it. For instance, cancer might be the stressor that affects not only patients, but also their relatives and caregivers. Cancer-related PTSD may occur at any stage of life (childhood and adolescence, adulthood, old age) and manifests itself in different ways. The first purpose of this paper is to describe each age group, thus showing PTSD from the perspective of children and teenagers, adults, and seniors. The second aim is to present the symptoms in the parents, siblings, and children of cancer patients. The third task is to describe risk factors that affect the occurrence of PTSD. Additionally, there are suggestions regarding issues which deserve future consideration.

NOWOTWORY J Oncol 2017; 67, 6: 359-364

Key words: PTSD, cancer, cancer patients, risk factors, relatives, children, adults, seniors

\section{Cancer as a stressor}

The diagnosis of cancer means one of over a hundred different diseases [1]. Therefore, given its broad character, cancer as a potential stressor is not easy to define. However, features common to all such as duration, size, and stage allow cancer to be distinguished from other health-related stressors. Furthermore, it is well-established that psychological distress can affect not only the patients, but the whole family [2,3], and stress or anxiety can occur at the time of diagnosis, treatment or regular follow-up tests [4]. For this reason, it is important to put patients in a broader perspective: from the moment when they start to raise suspicions of suffering from illness, until they recover completely [5, 6]. Patients may reveal a wide range of reactions. Stanton, Rowland, and Ganz [7] indicate that termination of the treatment, relapse, and survival 2 and 5 years after the diagnosis can generate similar reactions: symptoms of depression, fatigue, cognitive impairment, and pain.

\section{PTSD symptoms according to the DSM-V definition}

Prior to the fourth edition, the DSM did not include life-threatening disease as a stressor which could trigger Post- Traumatic Stress Disorder (PTSD) [8]. In the fifth edition [9], PTSD no longer belongs to the category of anxiety disorders, but to disorders related to trauma and stress. There are the following symptomatic criteria to identify it [10]. First of all, is experiencing a traumatic event, or being a witness to someone else experiencing one, or knowledge that a close person has experienced a traumatic incident or having repeated or extremely intense exposure to the aversive details of such an incident. Secondly are symptoms of intrusion (e.g. trauma-related memories or dreams) and avoidance: avoiding everything connected to the trauma by avoiding thoughts, conversations, people, places. Then come negative changes in mood and the presence of some cognitive processes (e.g. inability to remember important 
elements of the incident, distorted beliefs about the causes and consequences of the incident, an inability to experience positive emotions - all these symptoms have a persistent character). Next, there are changes in arousal and reactivity (e.g. careless behavior, excessively cautious behavior, problems with concentration). All these symptoms must occur for a minimum of one month, cause significant clinical danger or disturbances in functioning as a result of the disorder. Finally, there must be no association of these symptoms with the effects of taking any substances or having another medical condition.

The DSM-IV [8] also defines acute stress disorder (ASD). Although ASD is diagnosed with similar symptoms to PTSD, the main focus is on dissociative symptoms. Kangas, Henry, and Bryant [11] report that stronger dissociative symptoms at the time of cancer diagnosis were the only predictor of PTSD intensity after six months of observation. Despite the fact that the results of the study indicate that the diagnosis of ASD includes many people who later develop PTSD, there are also many cases of PTSD without prior diagnosis of ASD [12]. In contrast, Mehnert and Koch [13] indicate that only very few people in their study met the criteria for both PTSD and ASD.

\section{PTSD in the experience of cancer patients}

Although there is no doubt that the diagnosis of cancer and undergoing a healing process is a serious and often traumatic experience, researchers do not agree on what psychiatric symptoms should be expected in patients [14]. Undoubtedly, diagnosis and treatment may cause PTSD symptoms [e.g. 15-17], but it is difficult to discern a pattern, because many factors can influence the level of stress experienced. One such factor is the stage of the disease [18]. Women diagnosed at an early stage of the disease may experience less stress because their prognosis is better, and therefore the chances of recovery are higher. Meanwhile, women with late-stage disease can be expected to have a higher level of stress. A large number of such factors may give a rise to the problems of overdiagnosis [19], misdiagnosis [20], low rates of PTSD symptoms [18] and lack of recognition of a connection between cancer and PTSD [21]. Many types of cancer have been investigated, e.g. head and neck cancer [22], breast cancer [23-25], colorectal tumor [26], ovarian cancer [6], prostate cancer [27].

\section{Childhood and adolescence}

It was not always understood that children can suffer from PTSD [28]. However, we can observe a wide spectrum of PTSD symptoms in children as well [29]. When a person suffers from an illness as a child, PTSD symptoms may appear simultaneously to the illness (when the patient is a child) or occur later, when the patient is an adult. Thus, we can distinguish two perspectives of experiencing PTSD as a result of childhood cancer: in childhood and in adolescence.
Experiencing long-term stress as a result of illness is a natural process. Pelcovitz et al. [30] compared PTSD symptoms in children with cancer and abused children. They found more symptoms in children with cancer. Meanwhile, Phipps, Jurbergs and Long [31] demonstrated that the symptoms of post-traumatic stress disorder remain at a similar level in both children with cancer and their healthy peers. In this case, the adaptive style proved to be a more important factor than health condition. Children do not necessarily consider cancer as the most stressful factor in their lives [32]. They are able to adjust [33].

The other perspective is experiencing PTSD symptoms caused by having cancer in childhood as an adult. Going through a cancer in childhood may be a factor increasing the risk of PTSD symptoms in adulthood [34]. Hobie et al. [35] indicated that one-fifth of young people who overcame cancer in childhood still met the diagnostic criteria for PTSD. Similarly, Seitz et al. [36] observed that in adolescent cancer patients there is an increased risk of post-traumatic stress symptoms in adulthood. Ganz, Raz, Gothelf, Yaniv, and Buchval [37] showed that up to $29 \%$ of such patients met strict PTSD criteria, and only $16 \%$ did not experience any of the symptoms. Similarly, the experience of PTSD symptoms in adults who were recovering was observed by Langeveld, Grootenhuis, Voute, and De Haan [38]. Additionally, cancer survivors with PTSD are more prone to mental disease [39] and manifest more mental problems [40]. However, most of the survivors of childhood cancer do not describe cancer as the most stressful event in their lives [41].

\section{Adults}

PTSD is more often observed in cancer survivors than in the non-cancer population [42]. Most of the newly diagnosed patients meet the criteria for some PTSD symptoms, nevertheless a full PTSD diagnosis is rare [43]. The vast majority of the data comes from research on women [e.g.19, 44, 45].

Researchers observe a decrease of symptoms, especially after some therapies [46] however some patients experience persistent or even worse symptoms years afterward [47, 48]. Naidich and Motta [44] observed that women with breast cancer showed clear signs of PTSD, such as unwanted thoughts or avoiding specific behaviors. They pointed out that people who overcame the disease showed a higher level of depression. Depression and anxiety are often associated with PTSD [49]. Psychophysiological data support PTSD occurrence in cancer patients $[50,51]$. Meanwhile, Green et al. [18] indicate that only $3 \%$ of interviewed women met strict PTSD criteria related to the disease within 4-12 months after the end of treatment. Patients with breast cancer may also reveal a negative emotionality with very low PTSD symptoms [52]. Thus, although breast cancer has brought many ailments to patients, clinical signs of PTSD have not been observed. In the face of such results, it is difficult to 
qualify the disease as a stressor responsible for the occurrence of PTSD. Arnaboldi et al. [53] show that intrusion was negatively correlated with time elapsed since the diagnosis. However, they point out that patients with a higher intrusion level have problems with adjustment to the cancer as much as two years after the diagnosis. Cancer-related PTSD can be also a mediator for some cognitive dysfunctions [54,55] and influence sleep disturbances $[56,57]$.

\section{Seniors}

So far, researchers have devoted the least attention to the symptoms of PTSD in elderly people. This area requires deeper exploration for at least two reasons. First, the risk of cancer increases with age [58], so proportionally more patients may need psychological help in this age group. Second, taking into account the aging of society, seniors constitute an increasing proportion of the population. Age is an important factor that affects the ability to cope with a disease. Older women with breast cancer do better than younger people at the beginning of the diagnosis [59] and enjoy better quality of life [60]. Deimling, Kahana, Bowman, and Schaefer [61] show that the majority of older people with long-term cancer do not show clinical symptoms of PTSD, nonetheless they do have symptoms of depression and other symptoms resulting from the disease. In old age, people also experience other diseases more, which influences their general well-being [62].

\section{PTSD in cancer patients' relatives' experience}

The occurrence of cancer affects the whole family - not only patients, but also their relatives who support the ill and are exposed to stress. Therefore, there is a high probability that a member of such a family will experience symptoms of PTSD [63]. This might be a very undesirable situation, given the findings that social support is an important factor in keeping a positive mood in cancer patients [64], while caregivers may experience even more PTSD symptoms than patients [65]. In families where parents manifest more post traumatic stress symptoms, children with cancer exhibit more psychosocial problems [66].

Undoubtedly, when children get cancer, parents are the most vulnerable, as the closest persons in the child's environment. Mothers of children with cancer manifest PTSD symptoms [67] and to a greater extent than mothers of healthy children [68]. Similar results are observed in fathers [69, 70], although Masa'deh and Jarrah [71] indicate that mothers are at higher risk of PTSD. Iranmanesh, Shamsi, and Dehghan [72], supported by Pöder, Ljungman, and von Essen [73], observe that, indeed, mothers have more symptoms of post-traumatic stress than fathers. Infancy is a critical period in development, thus this moment generates many post traumatic stress symptoms [74]. Parents of newly diagnosed children show more symptoms than parents of long-time survivors [75]. Healthy parents parents are more susceptible to post-traumatic stress, as compared with their children diagnosed with cancer [76]. However both young patients and their parents exhibit PTSD symptoms long after treatment [77].

In addition to parents, a higher level of post-traumatic stress also occurs in siblings of cancer patients [78, 79]. Siblings experience more stress if their families function worse, if they experience lower parental acceptance and higher psychological control [80].

Children experience stress as a result of parents'illness in various ways. Their reactions may vary depending on the age, sex of the child and the parent [2]. Boyer et al. [81] observed that $20 \%$ of women with breast cancer and $13 \%$ of their daughters showed symptoms consistent with PTSD. However, if a mother explains her diagnosis to the children it may deepen the relationship between them [82].

\section{Risk factors}

So far, the following factors affecting the development of PTSD are known: perceived threat to life, experience of a trauma or severe stress in the past [83], social support, disease stage $[84,85]$, time elapsed from the end of treatment [84], decrease in physical fitness [85]. Particularly at risk of PTSD symptoms are younger women with reduced ability to use internal ways of dealing with emotions and these whose lives have changed significantly during the illness [86]. More intense forms of treatment also increase the incidence of PTSD in women [87]. This seems to be understandable, according to the view that the development of PTSD symptoms is associated with the level of the threat to life (and, therefore, the greater the risk, and hence, the more intense the therapy, the higher the probability of PTSD) [81]. Abbey, Thompson, Hickish, and Heathcote [88] indicate young people with more advanced stage and shortly after the end of treatment as a risk group.

Taïeb, Moro, Baubet, Revah-Lévy, and Flament [76] summarized the factors influencing the development of PTSD. They indicate that subjective assessment of life threat and beliefs about the disease are more important predictors than objective medical data. This is in line with the finding of Wachen, Patidar, Mulligan, Naik, and Moye [89] that the key role is played by individual characteristics and psychosocial factors. The time that has passed since the diagnosis of cancer is not an effective predictor of permanent symptoms. In the case of children, also the role of subjective factors and subjective judgment is greater than more objective medical data or stressors associated with treatment [90].

\section{Conclusions}

The aim of this article was not only to show the occurrence of PTSD during cancer disease, but also the possibility of occurrence of symptoms long after the end of the therapy, 
not only in patients, but also in their relatives. Undoubtedly, the experience of a life-threatening disease can contribute to the occurrence of severe stress at every stage of life. Reduction of PTSD symptoms may lead to better quality of life [91] and there is the great influence of social support [26]. Additionally, a proper help should be provided (for example: Kangas, Milross, and Bryant [92] propose an early cognitive-behavioral program for cancer-related PTSD). The described research suggests the following issues that deserve further consideration:

1. Cancer related PTSD is closely connected to medical condition. Different types of therapy are available and patients react in different ways to them, which in turn may influence their cognitive and psychosocial functioning. That is why all generalized conclusions should be formed very carefully.

2. There is still little information about cancer-related PTSD in seniors. As mentioned earlier, this is an important group because it constitutes a constantly increasing part of society $[93,94]$ and the potential incidence of cancer in the old age [95]. It is noteworthy that aging as a process brings also some quantitative and qualitative changes [96-98]. Thus, different outcomes should be expected from different age groups in the field of PTSD.

3. The other important aspect of the older age group are cases when they are parents of adult children with cancer. There is much research on symptoms in parents of young children (described earlier in this paper), however, little is known about the condition of older parents. Many factors may influence the relationship between older parents and adult children [99] and, undoubtedly, the experience of cancer is a difficult challenge for them.

4. There is a big difference in the number of studies carried out with women and men. Much of the research on the prevalence of PTSD in cancer patients involves women alone. The results of studies with men with cancer concern psychosocial factors [100, 101], but not PTSD directly. In general, the following differences have been observed: women are less likely to encounter PTSD-triggering events, but they meet more closely the PTSD criteria [102].

5. From a practical point of view, more attention should be paid to the family of cancer patients. One of the core elements of the PTSD diagnosis is being a witness to someone experiencing a traumatic event [9]. Caregivers and people closely related to the victims should be considered not only as a potential source of the social support [103-105], but also as people exposed to high stress.

6. Patients are very rarely screened for PTSD [106]. Cancer treatment brings not only physical problems, but also psychological issues. Proper psychological help is necessary in this case.

\section{Limitations}

The article shows that PTSD symptoms may occur in patients of all ages and vary in degree, however, it is worth noting that some of the cited studies refer to earlier definitions of PTSD, which differ from the one employed in this paper.

\section{Conflict of interest: none declared}

\author{
Monika Paleczna, MSc \\ Jagiellonian University \\ Institute of Psychology \\ ul. Ingardena 6 \\ 30-060 Kraków, Poland \\ e-mail:monika.paleczna@gmail.com
}

Received: 19 Jan 2018

Accepted: 3 Feb 2018

\section{References}

1. Allen F. Health psychology: theory and practice. Sydney: Allen \& Unwin, 1998.

2. Compas BE, Worsham NL, Epping-Jordan JE et al. When mom or dad has cancer: markers of psychological distress in cancer patients, spouses, and children. Health Psychol 1994; 13: 507-515.

3. Compas BE, Worsham NL, Ey S et al. When mom or dad has cancer: II. Coping, cognitive appraisals, and psychological distress in children of cancer patients. Health Psychol 1996; 15: 167-175.

4. Smith MY, Redd WH, Peyser $\mathrm{C}$ et al. Post-traumatic stress disorder in cancer: a review. Psychooncology 1999; 8: 521-537.

5. Tomich PL, Helgeson VS. Five years later: a cross-sectional comparison of breast cancer survivors with healthy women. Psychooncology 2002; 11: 154-69.

6. Gonçalves V, Jayson G, Tarrier N. A longitudinal investigation of posttraumatic stress disorder in patients with ovarian cancer. J Psychosom Res 2011; 70: 422-31.

7. Stanton AL, Rowland JH, Ganz PA. Life after diagnosis and treatment of cancer in adulthood: contributions from psychosocial oncology research. Am Psychol 2015; 70:159-174.

8. Frances A. Diagnostic and statistical manual of mental disorders:DSM-IV. Washington: American Psychiatric Association, 1994.

9. Diagnostic and statistical manual of mental disorders (DSM-5 ${ }^{\oplus}$. Ed. by American Psychiatric Association. Arlington, 2013.

10. Friedman MJ. Finalizing PTSD in DSM-5: getting here from there and where to go next. J Trauma Stress 2013; 26: 548-556.

11. Kangas $M$, Henry JL, Bryant RA. Predictors of posttraumatic stress disorder following cancer. Health Psychol 2005; 24: 579-585.

12. Kangas $M$, Henry JL, Bryant RA. Posttraumatic stress disorder following cancer: A conceptual and empirical review. Clin Psychol Rev 2002; 22: 499-524.

13. Mehnert A, Koch U. Prevalence of acute and post-traumatic stress disorder and comorbid mental disorders in breast cancer patients during primary cancer care: a prospective study. Psychooncology 2007; 16: 181-188.

14. Cordova MJ, Riba MB, Spiegel D. Post-traumatic stress disorder and cancer. Lancet Psychiatry 2017; 4: 330-338.

15. Andrykowski MA, Cordova MJ, Studts JL e al. Posttraumatic stress disorder after treatment for breast cancer: Prevalence of diagnosis and use of the PTSD Checklist-Civilian Version (PCL-C) as a screening instrument. J Consult Clin Psychol 1998; 66: 586-590.

16. Manne SL, Du Hamel K, Gallelli K et al. Posttraumatic stress disorder among mothers of pediatric cancer survivors: diagnosis, comorbidity, and utility of the PTSD checklist as a screening instrument. J Pediatr Psychol 1998; 23: 357-366.

17. Hahn EE, Hays RD, Kahn KL et al. Posttraumatic stress symptoms in cancer survivors: relationship to the impact of cancer scale and other associated risk factors. Psychooncology 2015; 24: 643-652.

18. Green BL, Rowland JH, Krupnick JL. Prevalence of posttraumatic stress disorder in women with breast cancer. Psychosomatics 1998; 39: 102-111.

19. Shelby RA, Golden-Kreutz DM, Andersen BL. Mismatch of posttraumatic stress disorder (PTSD) symptoms and DSM-IV symptom clusters in a 
cancer sample: exploratory factor analysis of the PTSD Checklist-Civilian Version. J Trauma Stress 2005; 18: 347-357.

20. Ubogy S, Olson KJ. The trauma symptom checklist for children and misdiagnosis of PTSD in a youth with acute lymphocytic leukemia: A brief report. J Child Adolesc Trauma 2014; 7: 13-15.

21. Gradus JL, Farkas DK, Svensson E et al. Posttraumatic stress disorder and cancer risk: a nationwide cohort study. Eur J Epidemiol 2015; 30: 563-568.

22. Posluszny DM, Dougall AL, Johnson JT et al. Posttraumatic stress disorder symptoms in newly diagnosed patients with head and neck cancer and their partners. Head Neck 2015; 37: 1282-1289.

23. Cordova MJ, Andrykowski MA, Kenady DE et al.. Frequency and correlates of posttraumatic-stress-disorder-like symptoms after treatment for breast cancer. J Consult Clin Psychol 1995; 63: 981-986.

24. Cordova MJ, Giese-Davis J, Golant M et al. Breast cancer as trauma: Posttraumatic stress and posttraumatic growth. J Clin Psychol Med Settings 2007; 14: 308-319.

25. Pérez S, Galdón MJ, Andreu Y et al. Posttraumatic stress symptoms in breast cancer patients: temporal evolution, predictors, and mediation. J Tauma Stress 2014; 27: 224-231.

26. Costa-Requena G, Ballester-Arnal R, Qureshi A et al. A one-year follow-up of post-traumatic stress disorder (PTSD) symptoms and perceived social support in cancer. Psycho-Oncologie 2014; 8: 89-93.

27. Mehnert A, Lehmann C, Graefen M et al. Depression, anxiety, post-traumatic stress disorder and health-related quality of life and its association with social support in ambulatory prostate cancer patients. Eur J Cancer Care 2010; 19: 736-745.

28. Davis L, Siegel LJ. Posttraumatic stress disorder in children and adolescents: a review and analysis. Clin Child Fam Psychol Rev 2000; 3: 135-154.

29. Butler RW, Rizzi LP, Handwerger BA. Brief report: the assessment of posttraumatic stress disorder in pediatric cancer patients and survivors. J Pediatr Psychol 1996; 21: 499-504.

30. Pelcovitz D, Libov BG, Mandel F et al. Posttraumatic stress disorder and family functioning in adolescent cancer. J Trauma Stress 1998; 11: 205-221.

31. Phipps S, Jurbergs N, Long A. Symptoms of post-traumatic stress in children with cancer: does personality trump health status? Psychooncology 2009; 18: 992-1002.

32. Sharp KM, Lindwall JJ, Willard VW et al. Cancer as a stressful life event: Perceptions of children with cancer and their peers. Cancer 2017; 123 : 3385-3393.

33. Phipps S, Klosky JL, Long A et al. Posttraumatic stress and psychological growth in children with cancer: has the traumatic impact of cancer been overestimated? J Clin Oncol 2014; 32: 641-646.

34. Schwartz L, Drotar D. Posttraumatic stress and related impairment in survivors of childhood cancer in early adulthood compared to healthy peers. J Pediatr Psychol 2005; 31: 356-366.

35. Hobbie WL, Stuber M, Meeske K et al. Symptoms of posttraumatic stress in young adult survivors of childhood cancer. J Clin Oncol 2000; 18: 4060-4066.

36. Seitz DC, Besier T, Debatin KM et al. Posttraumatic stress, depression and anxiety among adult long-term survivors of cancer in adolescence. Eur J Cancer 2010; 46:1596-1606.

37. DeKeyser Ganz F, Raz H, Gothelf D et al. Post-traumatic stress disorder in Israeli survivors of childhood cancer. Oncol Nurs Forum 2010; 37:160-167.

38. Langeveld NE, Grootenhuis MA, Voute PA et al. Posttraumatic stress symptoms in adult survivors of childhood cancer. Pediatr Blood Cancer 2004; 42: 604-610.

39. Meeske KA, Ruccione K, Globe DR et al. Posttraumatic stress, quality of life, and psychological distress in young adult survivors of childhood cancer. Oncol Nurs Forum 2001; 28: 481-489.

40. Rourke MT, Hobbie WL, Schwartz L. Posttrauamatic stress disorder (PTSD) in young adult survivors of childhood cancer. Pediatr Blood Cancer 2007; $49: 177-182$

41. Allen J, Willard VW, Klosky JL et al. Posttraumatic stress-related psychological functioning in adult survivors of childhood cancer. J Cancer Surviv 2017; Nov 3. doi: 10.1007/s 11764-017-0660-x.

42. Swartzman S, Booth JN, Munro A et al. Posttraumatic stress disorder after cancer diagnosis in adults: A meta-analysis. Depress Anxiety 2017; 34: 327-339.

43. Voigt V, Neufeld F, Kaste J et al. Clinically assessed posttraumatic stress in patients with breast cancer during the first year after diagnosis in the prospective, longitudinal, controlled COGNICARES study. Psychooncology 2017; 26: 74-80.
44. Naidich JB, Motta RW. PTSD-related symptoms in women with breast cancer. J Psychother Independ Practice 2000; 1: 35-54.

45. Cordova MJ, Studts JL, Hann DM et al. Symptom structure of PTSD following breast cancer. J Trauma Stress 2000; 13: 301-319.

46. Levine EG, Eckhardt J,Targ E. Change in post-traumatic stress symptoms following psychosocial treatment for breast cancer. Psychooncology 2005; 14: 618-635.

47. Andrykowski MA, Cordova MJ, Mcgrath PC et al. Stability and change in posttraumatic stress disorder symptoms following breast cancer treatment: a 1-year follow-up. Psychooncology 2000; 9: 69-78.

48. Chan CM, Ng CG, Taib NA et al. Course and predictors of post-traumatic stress disorder in a cohort of psychologically distressed patients with cancer: A 4-year follow-up study. Cancer 2017; 124: 406-416.

49. Ginzburg K, Ein-DorT, Solomon Z. Comorbidity of posttraumatic stress disorder, anxiety and depression: a 20-year longitudinal study of war veterans. J Affect Disord 2010; 123: 249-257.

50. Pitman RK, Lanes DM, Williston SK et al. Psychophysiologic assessment of posttraumatic stress disorder in breast cancer patients. Psychosomatics 2001; 42: 133-140.

51. Luecken LJ, Dausch B, Gulla V et al. Alterations in morning cortisol associated with PTSD in women with breast cancer. J Psychosom Res 2004; 56: 13-15.

52. Palmer SC, Kagee A, Coyne JC et al. Experience of trauma, distress, and posttraumatic stress disorder among breast cancer patients. Psychosom Med 2004; 66: 258-264.

53. Arnaboldi P, Lucchiari C, Santoro L et al. PTSD symptoms as a consequence of breast cancer diagnosis: clinical implications. Springerplus 2014; 3: 392.

54. Hermelink K, Bühner M, Sckopke P et al. Chemotherapy and post-traumatic stress in the causation of cognitive dysfunction in breast cancer patients. J Nat/ Cancer Inst 2017; 109(10).doi: 10.1093/jnci/djx057.

55. Yang J, Guo J, Jiang X. Executive function in cancer patients with posttraumatic stress disorder. Int J Psychiatry Med 2017; 52: 137-146.

56. Taylor TR, Huntley ED, Makambi K et al. Understanding sleep disturbances in African-American breast cancer survivors: a pilot study. Psychooncology 2012; 21: 896-902.

57. Lillis TA, Gerhart J, Bouchard LC et al. Sleep disturbance mediates the association of post-traumatic stress disorder symptoms and pain in patients with cancer. Am J Hosp Palliat Care 2017 [Epub ahead of print].

58. Yancik R, Ries LA. Aging and cancer in America. Demographic and epidemiologic perspectives. Hematol Oncol Clin North Am 2000; 14: 17-23.

59. Compas BE, Stoll MF, Thomsen AH et al. Adjustment to breast cancer: age-related differences in coping and emotional distress. Breast Cancer Res Treat 1999; 54: 195-203.

60. Park BW, Lee S, Lee AR et al. Quality of life differences between younger and older breast cancer patients. J Breast Cancer 2011; 14: 112-118.

61. Deimling GT, Kahana B, Bowman KF et al. Cancer survivorship and psychological distress in later life. Psychooncology 2002; 11:479-494.

62. Deimling GT, Brown SP, Albitz $C$ et al. The relative importance of cancer-related and general health worries and distress among older adult, long-term cancer survivors. Psychooncology 2017; 26: 182-190.

63. Kazak AE, Alderfer M, Rourke MT et al. Posttraumatic stress disorder (PTSD) and posttraumatic stress symptoms (PTSS) in families of adolescent childhood cancer survivors. J Pediatr Psycho/ 2004; 29: 211-219.

64. Benedict C, Dahn JR, Antoni MH et al. Positive and negative mood in men with advanced prostate cancer undergoing androgen deprivation therapy: considering the role of social support and stress. Psychooncology 2015; 24: 932-939.

65. Jia M, Li J, Chen C et al. Post-traumatic stress disorder symptoms in family caregivers of adult patients with acute leukemia from a dyadic perspective. Psychooncology 2015; 24: 1754-1760.

66. Nakajima-Yamaguchi R, Morita N, Nakao T et al. Parental post-traumatic stress symptoms as predictors of psychosocial problems in children treated for cancer. Int J Environ Res Public Health 2016; 13: E812.

67. Libov BG, Nevid JS, Pelcovitz D et al. Posttraumatic stress symptomatology in mothers of pediatric cancer survivors. Psychol Health 2002; 17: 501-511.

68. Brown RT, Madan-Swain A, Lambert R. Posttraumatic stress symptoms in adolescent survivors of childhood cancer and their mothers. J Trauma Stress 2003; 16: 309-318.

69. Barakat LP, Kazak AE, Meadows AT et al. Families surviving childhood cancer: a comparison of posttraumatic stress symptoms with families of healthy children. J Pediatr Psychol 1997; 22: 843-859.

70. Pai AL, Greenley RN, Lewandowski A et al. A meta-analytic review of the influence of pediatric cancer on parent and family functioning. $J$ Family Psychol 2007; 21: 407-415. 
71. Masa'deh R, Jarrah S. Post traumatic stress disorder in parents of children with cancer in Jordan. Arch Psychiatr Nurs 2017; 31: 8-12.

72. Iranmanesh S, Shamsi A, Dehghan M. Post-traumatic stress symptoms among Iranian parents of children during cancer treatment. Issues Ment Health Nurs 2015; 36: 279-285.

73. Pöder U, Ljungman G, von Essen L. Posttraumatic stress disorder among parents of children on cancer treatment: a longitudinal study. Psychooncology 2008; 17: 430-437.

74. Vernon L, Eyles D, Hulbert C et al. Infancy and pediatric cancer: an exploratory study of parent psychological distress. Psychooncology 2017; 26: 361-368.

75. Phipps S, Long A, Hudson M et al. Symptoms of post-traumatic stress in children with cancer and their parents: effects of informant and time from diagnosis. Pediatr Blood Cancer 2005; 45: 952-959.

76. Taïeb O, Moro MR, Baubet T et al. Posttraumatic stress symptoms after childhood cancer. Eur Child Adolesc Psychiatry 2003; 12: 255-264.

77. Ozono S, Saeki T, Mantani T et al. Factors related to posttraumatic stress in adolescent survivors of childhood cancer and their parents. Support Care Cancer 2007; 15: 309-317.

78. Alderfer MA, Labay LE, Kazak AE. Brief report: does posttraumatic stress apply to siblings of childhood cancer survivors? J Pediatr Psychol 2003; 28: 281-286.

79. Kaplan LM, Kaal KJ, Bradley L et al. Cancer-related traumatic stress reactions in siblings of children with cancer. Fam Syst Health 2013; 31: 205-217.

80. Long KA, Marsland AL, Alderfer MA. Cumulative family risk predicts sibling adjustment to childhood cancer. Cancer 2013; 119: 2503-2510.

81. Boyer BA, Bubel D, Jacobs SR et al. Posttraumatic stress in women with breast cancer and their daughters. Am J Family Therapy 2002; 30: 323-338.

82. Al-Zaben F, Al-Amoudi SM, El-deek BS et al. Impact of maternal breast cancer on school-aged children in Saudi Arabia. BMC Res Notes 2014; 7: 2-11.

83. Alter $C L$, Pelcovitz $D$, Axelrod A et al. Identification of PTSD in cancer survivors. Psychosomatics 1996; 37: 137-143.

84. Andrykowski MA, Cordova MJ. Factors associated with PTSD symptoms following treatment for breast cancer: test of the Andersen model. $J$ Trauma Stress 1998; 11: 189-203.

85. O'Connor M, Christensen S, Jensen AB et al. How traumatic is breast cancer? Post-traumatic stress symptoms (PTSS) and risk factors for severe PTSS at 3 and 15 months after surgery in a nationwide cohort of Danish women treated for primary breast cancer. Br J Cancer 2011; 104: 419-426.

86. Koopman C, Butler LD, Classen $C$ et al. Traumatic stress symptoms among women with recently diagnosed primary breast cancer.J Trauma Stress 2002; 15: 277-287.

87. Jacobsen PB, Widows MR, Hann DM et al. Posttraumatic stress disorder symptoms after bone marrow transplantation for breast cancer. Psychosom Med 1998; 60: 366-371.
88. Abbey G, Thompson SB, Hickish T et al. A meta-analysis of prevalence rates and moderating factors for cancer-related post-traumatic stress disorder. Psychooncology 2015; 24: 371-381.

89. Wachen JS, Patidar SM, Mulligan EA et al. Cancer-related PTSD symptoms in a veteran sample: association with age, combat PTSD, and quality of life. Psychooncology 2014; 23: 921-927.

90. Stuber ML, Kazak AE, Meeske K et al. Predictors of posttraumatic stress symptoms in childhood cancer survivors. Pediatrics 1997; 100: 958-964.

91. Ha BY, Jung EJ, Choi SY. Effects of resilience, post-traumatic stress disorder on the quality of life in patients with breast cancer. Korean $J$ Women Health Nurs 2014; 20: 83-91.

92. Kangas M, Milross C, Bryant RA. A brief, early cognitive-behavioral program for cancer-related PTSD, anxiety, and comorbid depression. Cogn Behav Pract 2014; 21: 416-431.

93. Piau A, Campo E, Rumeau P et al. Aging society and gerontechnology: A solution for an independent living? J Nutr Health Aging 2014; 18: 97-112.

94. Rosset E. Aging process of population. Elsevier, 2018.

95. Podolskiy DI, Lobanov AV, Kryukov GV et al. Analysis of cancer genomes reveals basic features of human aging and its role in cancer development. Nat Commun 2016; 7: 12157.

96. Glisky EL. Changes in cognitive function in human aging. Brain aging: models, methods, and mechanisms. In: Riddle DR (ed.). Brain aging: models, methods, and mechanism. Boca Raton: CRC Press, 2007; 19:3-20.

97. Fjell AM, Walhovd KB. Structural brain changes in aging: courses, causes and cognitive consequences. Rev Neurosci 2010; 21: 187-222.

98. Anderson ND, Craik Fl. 50 Years of cognitive aging theory. J Gerontol $B$ Psych Sci Soc Sci 2017; 72: 1-6.

99. Umberson D. Relationships between adult children and their parents: Psychological consequences for both generations. J Marriage Family 1992; 54: 664-674.

100. Kunkel EJ, Bakker JR, Myers RE et al. Biopsychosocial aspects of prostate cancer. Psychosomatics 2000; 41: 85-94.

101. Steginga SK, Pinnock C, Gardner M et al.. Evaluating peer support for prostate cancer: the Prostate Cancer Peer Support Inventory. BJU Int 2005; 95: 46-50.

102. Tolin DF, Foa EB. Sex differences in trauma and posttraumatic stress disorder: a quantitative review of 25 years of research. Psychol Bull 2006; 132: 959-992.

103. Leung J, Pachana NA, McLaughlin D. Social support and health-related quality of life in women with breast cancer: a longitudinal study. Psychooncology 2014; 23: 1014-1020.

104. Pfaendler KS, Wenzel L, Mechanic MB et al. Cervical cancer survivorship: long-term quality of life and social support. Clin Ther 2015; 37: 39-48.

105. Fong AJ, Scarapicchia TM, McDonough MH et al. Changes in social support predict emotional well-being in breast cancer survivors. Psychooncology 2017; 26: 664-671.

106. Golchin A, Dawson GA. Online survey of young adult cancer survivors and illness-related stressors. J Clin Oncol 2017; 35 Suppl: 33. 